\title{
La música de las Cantigas revela las ordenanzas de trazado de la ciudad medieval Alfonsina.
}

The Music of the Cantigas reveals the layout ordinances of the medieval city Alfonsina.

Recibido:11/11/2017

Aprobado: 09/02/2018

\section{Resumen:}

La común regularidad de las pueblas fundadas por Alfonso X en Castilla ha sido estudiada por prestigiosos investigadores del último siglo, quienes han coincidido en afirmar que la similitud geométrica de las mismas podría responder a una idea preconcebida de la ciudad. Sin embargo, la ausencia de documentos acreditativos de estas sospechas ha supuesto que muchos rechacen la intuición inicial y que subrayen la imposibilidad de encontrar las reglas de trazado responsables de esta regularidad. La presente investigación tiene como objeto descifrar las ordenanzas de trazado que guiaron la construcción de las ciudades alfonsinas y demostrar, mediante el análisis urbanístico de tres de ellas y el estudio de la sabiduría clásica redescubierta en la época, la relación existente entre las reglas de trazado de una ciudad y las reglas de composición musical. Poniendo de manifiesto que las leyes aritméticas y geométricas utilizadas para la composición de la música del Códice de Las Cantigas pudieron ser las mismas que se utilizaron para diseñar el patrón urbano regular.

\section{Palabras Clave:}

Alfonso X; ciudad medieval regular, música medieval.
Carmen de Tomás Medina ${ }^{1}$

\section{Key words:}

Alfonso X; Regular Medieval City; Medieval music.

\footnotetext{
${ }^{1}$ Nacionalidad española. Doctora en Arquitectura; profesora del Departamento de Urbanística y Ordenación del Territorio de la escuela Técnica Superior de Arquitectura: Universidad de Sevilla, España.
} 


\section{Introducción}

El gran número de pueblas fundadas por Alfonso X "El Sabio" (1252-1284) en la Castilla del siglo XIII confirman la brillante labor repobladora llevada a cabo por el rey sabio, y representan una buena muestra del esplendor urbano que se vivió en el reino. Estas fundaciones resultaron fundamentales en muchos casos para la labor de recuperación del territorio tras la Reconquista, y en otros, para la creación de nuevas entidades sociales en los dominios de la Corona (Serra, 1968). Fundó pueblas en Asturias, Galicia, El País Vasco, La Transierra y el Sur Peninsular, sin hacer distinción en su morfología entre las pertenecientes a las zonas fronterizas y las de interior, y contribuyendo a la estructuración, articulación, defensa y consolidación del reino de Castilla. La localización de las nuevas villas estuvo condicionada por los elementos del medio físico característico de cada región, sin embargo, estos elementos nunca desvirtuaron la esencia sobre la que se consolidó su trazado urbano: la regularidad.

La regularidad destaca como la principal característica de trazado en sus nuevas fundaciones, lo que provoca que independientemente de la localización se encuentre entre sus villas una similitud morfológica tal, que haga cuestionarse si la construcción de las mismas fue realizada conforme a unas normas de trazado.

Existen muchos estudios sobre los fenómenos de poblamiento de la España Medieval en la historiografía tradicional, como los de Lacarra (1948), S. Moxó (1978) ó García de Cortázar (1985). Son destacables los centrados en la labor repobladora del rey sabio como los de J.I Ruiz de la Peña (1981) y M. González Jimenez (2006), entre otros. Sin embargo, son menos frecuentes los que se centran en el análisis de la morfología urbana y se disminuye considerablemente el número cuando se trata de hablar de la geometría del trazado urbano.

El conocimiento de la ciudad medieval ha preocupado a reputados historiadores de los últimos tiempos, pero normalmente éstos han focalizado su interés en el aprendizaje de las funciones que se desarrollaban en la ciudad, su estilo de vida, sus relaciones sociales, etcétera; y han dejado de lado el entendimiento de la propia estructura urbana. No obstante, existen fuentes escritas que describen la ciudad medieval (Arizaga, 1996); iconografía histórica que permite entender su fisonomía (Frugoni, 1991), siendo especialmente significativa a partir del siglo XVI con la utilización de la perspectiva; y cartografía histórica ${ }^{1}$, que posibilita el reconocimiento, desde de un determinado momento de la historia, de la evolución urbana de la ciudad.

La historia urbanística, o lo que es lo mismo, el estudio de la ciudad como objeto físico, que debe su forma a los hechos históricos que se han sucedido a lo largo del tiempo, comenzó a ver la luz en la Italia de los sesenta. Reconocidos arquitectos como Muratori (1960), Rossi (1982), Aymonino (1983) ó Caniggia (1981) comenzaron a centrar su trabajo investigador en el análisis formal de la ciudad, desarrollando una nueva corriente analítica que recurría al tipo edificatorio como concepto en el estudio de la forma urbana. Desarrollaron estudios morfotipológicos que proponían utilizar el plano parcelario como fuente de todo conocimiento, como el lugar donde se manifestaba la interacción entre la tipología edificatoria y la morfología urbana (Betrán, 1994). A partir de los años setenta fueron muchos los estudios sobre la forma urbana que se acogieron a esta nueva corriente analítica, y que creyeron firmemente, como dijo Sainz Guerra (1990), que "la tipología, la parcelación, la manzana (...) y la trama urbana, forman esa cadena que llamamos "tipológica" ó "morfotipológica" que sienta la base esencial de la interdependencia de los distintos elementos en la ciudad. Sin embargo, es preciso subrayar que aunque el empleo del método descrito consiguió explicar la morfología de la ciudad en distintas etapas de la historia, nunca ha sido el método perfecto, porque también contiene errores manifiestos.

Aun así, es del todo cierto que las fuentes que mejor posibilitan el entendimiento de los elementos que configuran la estructura urbana de las antiguas villas medievales y que además posibilitan el conocimiento de sus esquemas de trazado, son aquellas que se centran en observar directamente el espacio urbano de la ciudad (Arizaga, 1996), prestando especial atención a las transformaciones de la red viaria, de los parcelarios ${ }^{2}$ y de

\footnotetext{
${ }^{1}$ Entiéndase como cartografía histórica la documentación cartográfica creada por motivos militares. Hay que esperar hasta el s.XVIII y sobre todo al XIX para encontrar rigurosos planos de las principales ciudades españolas. El atlas de España elaborado por Coello y Madoz son en paradigma de esta representación. ${ }^{2}$ Siempre que se estudie la ciudad como objeto físico, es de gran utilidad estudiar planos parcelarios históricos porque nos dan una aproximación muy exacta de la realidad constructiva de la ciudad.
} 
su arqueología urbana ${ }^{1}$. En este sentido, autores como Torres Balbás, García y Bellido, Cervera, Chueca Goitia y Bidagor (1954), López Alsina (1976), Sánchez Herrero (1981), ó Benito Martín (2000) han llevado a cabo un exhaustivo estudio de los elementos responsables de la morfología de la ciudad medieval.

Pero sin duda, entre los que más han profundizado en la materia y han aportado interesantes conclusiones para el entendimiento de la ciudad Alfonsina, pormenorizando en el estudio de los esquemas de trazado regular, destacan Arizaga Bolumburu (1978) y Ruiz de la Peña (1981), aunque también Medianero Hernández (2004) y Bielza de Ory (2002) se han pronunciado al respecto. Sin embargo, es Betrán Abadía (1992), el que nos acerca al pensamiento de la época. Profundiza en las premisas sobre las que se desarrolló el pensamiento tomista y en lo que supuso el Renacimiento cultural, haciéndonos reflexionar en el nuevo modo de pensamiento del hombre del bajo Medievo, en todo lo relativo a sus nuevas ideas, esas que podrían sustentar la construcción de la ciudad regular. De tal manera que aún sin referirse explícitamente a la ciudad Alfonsina aporta conclusiones definitivas que corroboran nuestra sospecha.

Arizaga Bolumburu dijo textualmente en su análisis sobre muchas de las ciudades regulares levantadas por el rey sabio en Guipuzcoa: "viendo todo esto nos preguntamos si no existiría algún tipo de normas para la construcción de las villas. En la documentación utilizada, cartas pueblas, fueros y las Partidas de Alfonso X, no hemos encontrado nada que nos haga suponer tal cosa; sin embargo, no podemos rechazar la hipótesis de la existencia de normas para la construcción de villas o ciudades" (Arizaga, 1978:45).

Betrán Abadía también reflexionó sobre la morfotipología como método de estudio para el entendimiento de las distintas etapas históricas vividas por una ciudad e hizo referencia a una frase de Vitrubio para explicar el modo de construcción de la misma en cualquier etapa de la historia: "establecidas las calles mayores y menores, se sigue tratar de las áreas oportunas para el uso común de la ciudad, como son los templos sagrados, foro y demás lugares públicos", añadiendo textualmente su opinión, "la parcela, producto de la fragmentación de las manzanas (...) antecede al tipo y, en la parte que le toca, la determina, Cualquier texto que se consulte, desde este de Vitruvio hasta nuestros Planes Generales, pasando por Alfonso X, Tomás de Aquino o Felipe II, confirma este orden de prioridades" (Betrán, 1994:150).

Medianero Hernández afirmó que: "el rey Alfonso X desarrolló una política urbana tendente a la cuadrícula correspondiente con la teoría sostenida en Las Partidas" (Medianero, 2004:127). Ruiz de la Peña, por su parte, resaltó el carácter del plano regular en cuadrícula de la puebla de Llanes justificando su trazado con lo dispuesto por Alfonso X en la ley XX tit. XXIII de la Partida III ${ }^{2}$ "un eje viario principal que todavía hoy conserva su originario nombre de calle mayor, une las puertas que se abren en los lienzos sur y norte del recinto amurallado, paralela a ella se desarrolla una segunda calle longitudinal de menor importancia, cortando ambas la transversal que tiene su arranque en otras de las puertas de acceso a la villa, abierta en la fachada Este de la cerca, y desemboca en la amplia plaza de la iglesia parroquial" (Ruiz de la Peña, 1981:120).

Y Bielza de Ory en sus ivestigaciones sobre la cuadrícula de la ciudad aragonesa también admitió que el modelo regular urbano, fue objeto de atención previamente por Alfonso X "El sabio" en la Castilla del siglo XIII (Bielza de Ory, 2002).

Es decir, todos se pronuncian directa ó indirectamente sobre la posible existencia en el bajo Medievo, de unas reglas de trazado urbano que guiase la construcción de las ciudades alfonsinas, sobre una idea preconcebida de la ciudad, en definitiva, sobre una planificación previa. Pero ninguno las especifica, ni encuentra documentos que acrediten esta sospecha. Llegado este momento y como dijo Arizaga Bolumburu el hecho de no haber encontrado nada no hace que "podamos rechazar la hipótesis de la existencia de normas para la construcción de villas o ciudades", en definitiva, no hace que se pueda obviar lo intuido.

Así, de la meditación de estas palabras, y aferrándonos a la hipótesis de que la similitud morfológica descrita responde a un patrón común pensado y elaborado por Alfonso X "El Sabio", surge la presente investigación, cuyo objeto se centra en descifrar las reglas de trazado implícitas en las ciudades alfonsinas, así como en

\footnotetext{
${ }^{1}$ Empleamos este nombre cuando el objeto de estudio es el conjunto de la ciudad, es decir se busca la reconstrucción de la formación de la villa a través del tiempo.

${ }^{2}$ En el valioso documento Alfonsino, bajo el título "en qué manera deven aposentar la hueste", se establece que debe ejecutarse "según la fación del lugar, si fuere luenga, quadrada o redonda ...si la hueste fuere redonda, deven dexar una carrera ancha de parte de dentro en derredor de las tiendas de los hombres honrrados, e las otras de los pueblos; si fuere luenga, dexar en medio que sea toda derecha; e si fuere quadrada deven dexar dos o fasta quatro, las unas en luengo e las otras en travieso.."
} 
localizar el documento que las contiene, y cuyo propósito se enfoca en definirlas como las directrices necesarias para conseguir desarrollos urbanos de calidad. De tal manera que teniendo en cuenta lo que supuso en el pensamiento de la época el redescubrimiento de las teorías postuladas por los clásicos, en especial la conocida influencia Aristotélica en el pensamiento tomista, y la agrupación que se hizo con las artes liberales para la difusión del conocimiento ${ }^{1}$, finalmente se encuentran, en uno de los documentos del fantástico legado cultural que dejó el rey sabio, las ansiadas normas de trazado, escritas utilizando un lenguaje muy diferente al empleado tradicionalmente: el lenguaje musical.

\section{Método}

El trabajo se desarrolla apoyándose en fuentes historiográficas, iconográficas, cartográficas, y arqueológicas que sirven de base para una aproximación al conocimiento de la morfología de la ciudad medieval. Aunque será, mediante el análisis de la estructura urbana de tres ciudades fundadas por el rey sabio en ámbitos geográficos muy diferentes: Villaviciosa, Mondragón y La Puebla del Río; a partir del conocimiento de las teorías postuladas por los clásicos redescubiertos durante el Renacimiento cultural que se produjo en la época; y a raíz del estudio del sistema compositivo utilizado en la música de Las Cantigas, cuando descubriremos las verdaderas reglas de trazado que guiaron la construcción de la ciudad Alfonsina.

La identificación y el análisis de la trama urbana se lleva a cabo utilizando el dibujo como instrumento, y los fondos documentales disponibles en el archivo general de Simancas, en especial la colección de mapas, planos y dibujos, así como los recogidos en la Biblioteca Nacional, o en los fondos cartográficos del Instituto Geográfico Nacional, como fuentes principales de información. Si bien el instrumento apuntado es el utilizado habitualmente para representar una ciudad, se deja de lado la planimetría tradicional, evitando que el medio empañe la consecución del fin, y se utiliza como base para el dibujo la ortofoto de la ciudad.

Es decir, se apuesta por el levantamiento del tejido medieval de la ciudad sobre una imagen área que corregida digitalmente representará una proyección ortogonal sin los efectos de la perspectiva, y en la que será posible realizar mediciones sin tener que recurrir a la planimetría de la ciudad, porque en ella se combinan, gracias a la técnica descrita, las propiedades geométricas de un plano con el detalle de una fotografía, lo que hace que en ningún momento se prescinda de las características necesarias para hacer un correcto levantamiento de la ciudad. Con ello conseguiremos una identificación certera a partir de la realidad actual que evitará márgenes de error y que será fácil de realizar e interpretar. Y que nos permitirá comprobar a partir de la comparación con la cartografía histórica, que ni la evolución de las alineaciones, ni las transformaciones morfológicas de sus parcelas ni la reestructuración de los viarios, han impedido que llegue hasta nuestros días la esencia con la que se diseñó ese patrón urbano: la regularidad.

El estudio de la influencia de los tratados clásicos en los nuevos trazados urbanos se lleva a cabo gracias a la consulta de numerosas fuentes bibliográficas, entre las que destacan las interesantes aportaciones de Betrán Abadía (1992).

Y el análisis de la música escrita en Las Cantigas es posible gracias a la consulta de los tratados de Boecio, San Agustín, Salinas y a los brillantes estudios de Fernández de la Cuesta y de López Elum (2005). A partir de las cuales y en conjunción con los resultados del análisis urbano y las aportaciones de grandes pensadores clásicos como Pitágoras, Aristóteles, Arquitas,

${ }^{1}$ Alcuino fue el motor principal del renacimiento cultural, y tratando de recuperar el saber clásico centró los programas de estudio en torno a las siete artes liberales distribuyéndolas en dos grupos fundamentales: el Trivium que se centraba en la enseñanza de la elocuencia y lo formaban la gramática, la retórica y la dialéctica y el Quadrivium que se basaba en las enseñanzas de las matemáticas a partir del estudio de la astronomía, la aritmética, la geometría y la música. 
Anaximandro, ó Euclides, se llega a la conclusión de que las proporciones utilizadas para la composición de la música del Medievo podrían ser las mismas que se usaron para el levantamiento de la traza de la ciudad.

\section{La Puebla de Villaviciosa}

En Galicia, a los pies del arroyo de la Fontanina, en el profundo estuario del Buetes, fue fundada en 1270 por Alfonso X "El Sabio" Maliayo, la actual Villaviciosa. Con un trazado regular y en un recinto fortificado, se levantaba el tejido urbano en base a dos ejes longitudinales que convergían en uno de los principales puntos de acceso a la villa y otros dos ejes transversales que lo estructuraban. Las casas se alineaban a lo largo de las calles de forma compacta, y la iglesia se situaba junto a la puerta, pero sin sacralizar la traza y pasando a dialogar con la plaza, que emergía como nuevo elemento urbano.

El 17 de Octubre de ese mismo año el rey le otorgó una carta puebla basada en el mismo esquema que el resto de las expedidas en Galicia. Contenía un preámbulo en el que el monarca exponía las motivaciones de la concesión; donación a los moradores de la circunscripción de los realengos y derechos que el monarca tenía en ella, reservándose el patronazgo de las iglesias; la fijación del lugar de asentamiento del nuevo núcleo; la concesión de celebrar mercado; remisión expresa al fuero de Benavente para la administración de la justicia; donación del alfoz de la puebla y su delimitación mediante referencias geográficas precisas; fijación de la contraprestación económica que los moradores debían de dar al monarca y la exención formulada genéricamente de todo tipo de prestación a los pobladores, excepto las de moneda y hueste (Ruíz, 1981).
Figuras 1 y 2: Identificación y levantamiento de la ciudad medieval de Villaviciosa.

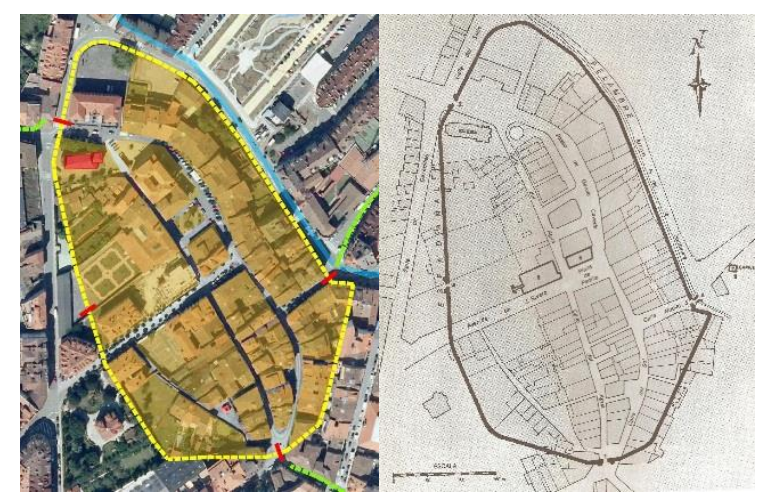

Fuente: Izquierda: Elaboración propia sobre ortofoto digital capturada del visor del Ministerio de Fomento del Gobierno de España. Derecha: Levantamiento de la ciudad extraído de "Las polas...." De Ruíz de la Peña, 1981.

A raíz del reconocimiento del tejido medieval (figura 1), se observa una ligera inclinación de $30^{\circ}$ hacia el Oeste de su trama urbana. Trama articulada a partir de dos ejes principales trazados en dirección Noroeste-Sudeste y otros dos ejes, de menor envergadura, transversales. Todos ellos, nacidos de acuerdo con la directriz que marcaban los antiguos caminos a su encuentro con la muralla, y que provocaron con su intersección en la misma, la apertura de las puertas de la ciudad. Las manzanas se subdividen en parcelarios con acceso desde las calles que las enmarcan (figura 2). La regularidad destaca en su trazado viario y subyace en la composición de su tejido, que resulta armónico, producto del rectángulo áureo en el que queda enmarcado todo el recinto y de la aparente simetría existente en torno al eje principal. La iglesia deja de presidir el conjunto y comienza a estar integrada en él, provocando tras su implantación la aparición de la plaza que empieza a vislumbrarse como la nueva generatriz urbana.

La utilización de la ortofoto como base para el reconocimiento del recinto urbano posibilita identificar las diferentes cubiertas que coronan tejido residencial, las cuales nos aportan información sobre las servidumbres y el orden de prioridades con el que se construyó la ciudad. También nos permiten conocer la primera división parcelaria, que tal y como se observa en las imágenes, 
coincide con el levantamiento de Uría que recogió en su libro Ruiz de la Peña (1981).

\section{La Villa de Mondragón}

En el valle del Deva, Guipuzcoa, Alfonso X "El Sabio" le otorgó en 1260 carta puebla a la antigua aldea de Arrasate (Achon, 1995), que pasó a llamarse Mondragón. Con un trazado regular y delimitado por un recinto de forma ovalada, en el que el caserío hacía las veces de fortificación, se levantaba el tejido urbano, estructurado en base a tres ejes longitudinales y otros tres ejes transversales. Las casas se alineaban a lo largo de las calles de forma compacta, y la iglesia se situaba centrada en el tejido, dialogando con la plaza y convirtiéndose junto con ella, en el nuevo centro neurálgico de la trama urbana.

\section{Figuras 3 y 4: Identificación y levantamiento de la ciudad medieval de Mondragón.}

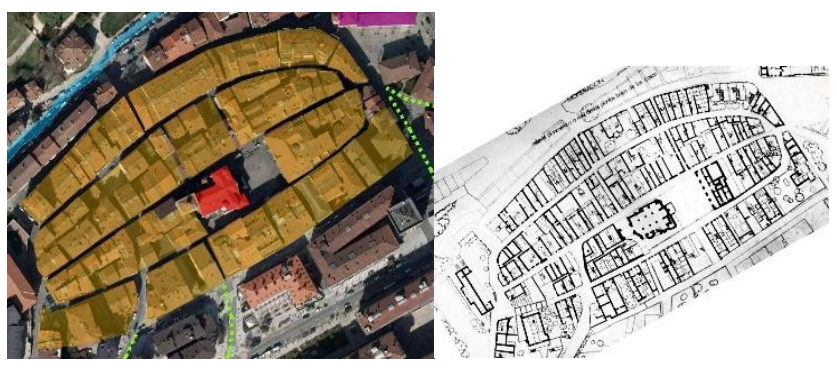

Fuente: Izquierda: Elaboración propia sobre ortofoto digital capturada del visor del Ministerio de Fomento del Gobierno de España. Derecha: Levantamiento del parcelario de la ciudad realizado por Francisco Coello, siglo XIX. Archivo

Su carta puebla era un documento breve, muy diferente del utilizado para la instrumentación jurídica de las pueblas Gallegas, donde, como hemos visto, se solían explicar detenidamente los motivos fundacionales y detallar aspectos como las donaciones a los moradores de la circunscripción, el lugar concreto para el asentamiento del núcleo, la concesión del privilegio de celebrar mercado y otros. En la de Mondragón únicamente se incluía una remisión al fuero de Vitoria, sin especificar ningún tipo de privilegio, ni normas obligatorias para los pobladores del lugar. Era el fuero de Vitoria el que le proporcionaba la instrumentación jurídica necesaria para que el núcleo funcionase como villa. El fuero regulaba aspectos sociales, civiles y administrativos, hablaba de los derechos y deberes de los pobladores, y regulaba el comercio. También reconocía al rey como máxima autoridad de las tierras, y citaba al resto de las autoridades que gobernaban la villa. Mencionaba los componentes urbanos más importantes de la ciudad, pero no establecía ninguna regulación urbanística que dirigiese el levantamiento de la trama urbana.

Tras la identificación de su recinto urbano (figura 3), se observa que el tejido fue trazado con una forma ovalada en la que el caserío hacía las veces de fortificación. Las revueltas con los musulmanes quedaban lejos y ya no era necesaria la muralla utilizada en Villaviciosa, aunque la ciudad seguía necesitando sentirse recogida y protegida. El elemento muralla había evolucionado. La traza presenta una inclinación de $60^{\circ}$ hacia el Este (Arizaga, 1978), y se articula en base a tres ejes longitudinales trazados en paralelo al cauce del río y otros tres ejes transversales nacidos de la directriz que marcaban los antiguos caminos que llegaban a la ciudad a su encuentro con el caserío que hacía las veces de fortificación. Las manzanas interiores son dobles, con salida a ambas calles, y las exteriores son simples, potenciando el papel de muralla que ejercía la masa residencial (figura 4). La utilización del número tres como referencia recuerda al patrón urbano establecido en la Jerusalén celestial. Patrón caracterizado por la regularidad, también implícita en la ciudad de Mondragón y patente en las proporciones utilizadas en el levantamiento de su tejido urbano, diseñado en su totalidad dentro de dos rectángulos construidos en proporción áurea, imprimadores sin duda de la armonía de la ciudad. Armonía regida de nuevo, por la simetría, articulada en torno al eje principal, donde se ubica la iglesia, lejos de las puertas de acceso a la ciudad, sin dominar el conjunto, y sin sacralizar su traza, y en perfecta sincronía con la plaza que aparece centrada en la 
composición, construida en base a las proporciones áureas, e identificada como el nuevo elemento generador, articulador y organizador del espacio público.

De nuevo la utilización de la ortofoto nos permite conocer, a través de las cubiertas, la primera división parcelaria de la ciudad, que coincide con el levantamiento hecho por Coello, y que pone de manifiesto la relevancia del concepto de propiedad en la ciudad medieval. Pues el hecho de que existiera implicaba sin duda alguna una planificación previa de la misma.

\section{La Puebla del Río}

A orillas del Guadalquivir, en Andalucía, en un promontorio sobre el nivel de mar, Alfonso X donó en 1272 para su constitución como núcleo urbano, La Guardia, antigua alquería de Sevilla. El recinto delimitado fue muy similar al de las ciudades anteriormente descritas, y en él se levantó La Puebla del Río, también caracterizada por la regularidad de su trazado urbano. Se estructuraba en torno a dos ejes longitudinales y otros tres transversales. Las casas se alineaban a lo largo de las calles de forma compacta, y la iglesia se situaba centrada en la composición, aunque no en el tejido.

Otorgada la carta puebla para llevar a cabo el levantamiento de la villa el rey le concedió privilegio rodado (figura 5), documento donde se fue adaptando a través del tiempo lo dispuesto en su carta de fundación (Pardo, 2010). En él se delimitó el recinto de la villa y las condiciones para el desarrollo de la nueva población, lo que provocó confusión respecto a la titularidad de los terrenos de las Marismas (Borrero, 2010), por lo que Sevilla y la Puebla se disputaron su posesión. La Carta fundacional y el privilegio rodado de $\mathrm{La}$ Puebla procuraban, como en los casos anteriores, la regulación de los aspectos sociales, civiles, administrativos, etcétera de la villa, pero de nuevo, no establecían determinaciones para regular la ordenación urbana.
Figuras 5 y 6: Privilegio rodado de la Puebla del Río e identificación de la ciudad medieval.

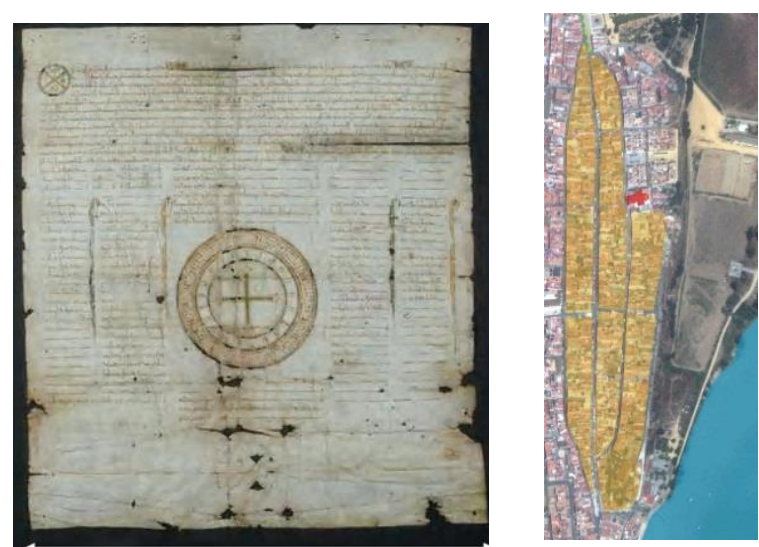

Fuente: Izquierda: Privilegio rodado en el Archivo Histórico Municipal del Ayuntamiento de la Puebla de Río. Derecha: Reconocimiento de la ciudad. Elaboración propia sobre ortofoto digital capturada del visor del Ministerio de Fomento del Gobierno de España.

Al dibujar la forma urbana de la antigua villa medieval (figura 6) se reconocen todas las características mencionadas anteriormente en la descripción de la puebla de Villaviciosa y la villa de Mondragón. El recinto tiene forma ovalada y está protegido por el propio caserío que ejerce de muralla. La traza se articula en torno a ejes longitudinales y transversales que dibujan un patrón urbano regular, en el que de nuevo está implícito, aunque esta vez en la disposición de las manzanas el número tres (tres filas). Todas las manzanas son dobles, con salida a ambas calles. Y el conjunto se desarrolla dentro de tres rectángulos que también respetan la proporción áurea y que a su vez le imprimen la armonía a la ciudad, armonía articulada, de nuevo, en torno a un eje de simetría que parece recorrer todo el conjunto urbano. En este caso, la iglesia también se sitúa en el centro de la composición, aunque no centrada en el tejido, quizá por la inicial función defensiva con la que se fundó.

Como vemos las tres ciudades analizadas tienen, a pesar de localizarse en ámbitos geográficos muy lejanos y diferentes, formas y trazados similares que parecen nacer de un mismo patrón urbano, que va cambiando de acuerdo con la evolución de las circunstancias sociales y 
políticas de la época, pero que responde a un común denominador: la regularidad. Una regularidad gestada en torno a la simetría y a unas proporciones numéricas que subyacen en sus trazados, y que fueron utilizadas para conseguir esa relación armónica existente entre el espacio público y privado de la ciudad.

En sus levantamientos se identifican las premisas urbanas citadas en las siete partidas promulgadas en 1263 por Alfonso X "El Sabio" (San Martín, 1872). Responden a la definición de ciudad, eligieron correctamente el lugar de asentamiento, cumplen con los requisitos para la construcción de las murallas y la edificación de las casas, con lo establecido para el levantamiento de las iglesias e incluso con lo dispuesto para el respeto del espacio público, de las calles y de las plazas. Premisas que no dejan de ser disposiciones jurídicas, carentes de envergadura para la formalización del espacio urbano. Queda en evidencia que únicamente con ellas era imposible el levantamiento de la ciudad.

En definitiva, en todos los documentos promulgados por el rey sabio para regular el levantamiento de los núcleos, queda claro el régimen jurídico al que debían de atenerse las ciudades del reino, y se señalan algunos de los elementos urbanos más importantes de la ciudad. Sin embargo, no son suficientes para justificar el levantamiento de las pueblas, su similitud morfológica ó la común regularidad de su trazado urbano. La reiterada perfección geométrica de las tramas de sus villas debió de responder a unas pautas pensadas y elaboradas previamente a la ejecución de sus trazados, a unas ordenanzas y a una planimetría que dirigiese el levantamiento de la ciudad, en definitiva, a unas normas que, contenidas en unos documentos, justificasen la planificación urbana.

\section{El Renacimiento Cultural}

Durante el bajo Medievo se redescubrieron importantes estudios y tratados de la antigüedad clásica, que gracias a la impecable labor de la escuela de traductores de Toledo fueron difundidos. Tras el oscurantismo de la alta Edad Media, el efervescente renacimiento cultural tuvo grandes repercusiones en el pensamiento del hombre de la época, que rechazó, siguiendo las ideas postuladas por Tomás de Aquino (1224-1274), contemporáneo a Alfonso X, el antiguo sistema ideológico centrado en la divinidad y defendió un nuevo sistema centrado en el aristotelismo, basado en la lógica y el racionalismo defendido por la vieja democracia ateniense para los hombres libres e iguales.

Tomás de Aquino refutó la secularización del pensamiento y sus ideas supusieron la consagración de la autonomía de la razón. Recuperó el marco de pensamiento aristotélico y admitió que el acto de creación no sólo provenía de Dios, defendiendo la función creadora del hombre mediante el pensamiento y la operación (Betrán, 1992). Aquino definió el pensamiento como la elaboración de una idea en la mente del creador de la obra, y la operación como la materialización de la misma a raíz de las ideas consagradas en el pensamiento. Afirmaba que la idea se produce desde los principios universales definidos en cada disciplina, y que por tanto es la esencia de cualquier creación humana, creación que deriva de una esencia universal. Según escribió en esta frase: "el resplandor de la forma sobre las partes de la materia proporcionadas", para él cada creación artificial no era un fenómeno aislado, provenía en realidad, de una regla perfectamente codificada, lo que implicaba que cualquier creación necesitara de una predeterminación de sus leyes de creación.

Figura 7: Quadrivium pitagórico.

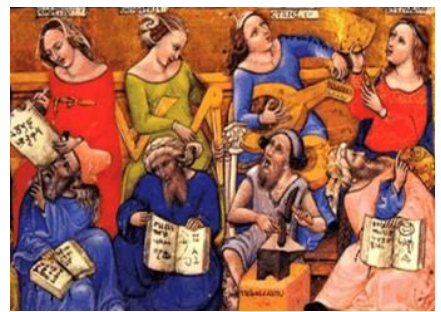

Fuente: Códice de Nicolo da Bologna Las Virtudes y las Artes de 1355. Biblioteca Ambrosiana de Milan 
Por esto la nueva ciudad del siglo XIII dejó de ser, en coincidencia con los postulados tomistas y según describe Betrán Abadía (1992:194), “el lugar simbólicamente dispuesto en el que una comunidad se aglutina en torno a la protección que brinda el poderoso" y pasó a ser "la expresión coherente de una nueva colectividad de hombres que están dotados de una organización propia". En definitiva, y como él mismo subrayó la nueva expresión paradigmática de esa forma urbana que se desarrolló en el bajo Medievo, era la ciudad hipodámica que tanto alababa Aristóteles. La nacida de la regularidad, la soberbiamente ortogonal en la que el espacio público se imponía al privado, organizándolo y estructurando, aquella que con su trazado garantizaba la igualdad de los hombres.

El renacimiento cultural provocó también la recuperación de la formación en los estudios de las artes liberales, respetando la agrupación Alcuiniana del Trivium y el Quadrivium, encabezadas por la elocuencia, la primera y por las matemáticas, la segunda. El Quadrivium Pitagórico (figura 7), como lo llamó Boecio, integraba las cuatro artes que Pitágoras había señalado años atrás como fundamentales para el entendimiento del universo: la astronomía, la geometría, la aritmética y la música. El reputado filósofo griego afirmaba que todas tenían la misma esencia, y que entre ellas existía un vínculo indisoluble, lo que hacía que no fuese posible el entendimiento aislado de ninguna de ellas.

Por su parte Tomás de Aquino llegó a comparar el acto fundacional de una ciudad con el origen del mundo, comparación sobre la que reflexiona Betrán Abadía (1992:196) afirmando textualmente que: "esta comparación implica el aislamiento de un momento preciso en el que se dispone su fundación, lo que implica una concepción previa de las características de la ciudad, en definitiva, su planificación".

Llegado este momento, y en consonancia con lo descrito, podría decirse que la ciudad hipodámica enaltecida por Aristóteles, fue el principal referente urbano de las pueblas construidas en el siglo XIII, y de acuerdo con el concepto de creación definido por Tomás de Aquino, también pudo ser la base para la elaboración de las reglas del trazado urbano. Reglas que, basadas en la regularidad como garante de una sociedad homogénea, donde ningún hombre gozase de privilegio alguno y donde todos eran iguales, se habrían elaborado respetando la agrupación Alcuniana del Quadrivium, lo que implicaría que, según lo especificado en líneas anteriores, la astronomía, la geometría, la aritmética y la música serían los verdaderos cimientos de la ciudad. En definitiva, se podría afirmar que en el estudio de la conjunción de las artes agrupadas en el Quadrivium podrían encontrarse las ordenanzas de trazado que guiaron la construcción de la ciudad alfonsina.

Resulta evidente, que, si entendemos la concepción previa de la forma urbana como un paso fundamental para la fundación de una ciudad regular, las tres primeras artes citadas serían absolutamente necesarias para el trazado de un plano, ó para la representación pictórica de una ciudad, pero la música, a priori, quedaría fuera de lugar. No obstante, es preciso conocer la representación cartográfica e iconográfica de la época para atestiguar lo descrito.

En el Medievo la representación cartográfica sufrió un profundo retroceso respecto a la cartografía del mundo clásico. La representación del mundo durante el cristianismo se basó en fundamentos religiosos y con ellos aparecieron las cosmografías, que difundieron las teorías dominantes sobre la forma de creación del mundo (Arizaga, 2010). Hay que esperar hasta el s.XVI para vislumbrar las primeras vistas urbanas nacidas como consecuencia de la generalización de las leyes de la perspectiva y especialmente hasta el s.XVIII encontrar rigurosos planos urbanos levantados a escala y con un absoluto control de la topografía urbana, en los que se aprecia claramente la geometría del trazado viario, además de la ubicación de los elementos singulares de la ciudad. Por lo tanto, en caso de existir unas reglas de trazado, fruto de una planificación previa y concebida en base a las cuatro artes liberales que integraban el Quadrivium, nunca habrían podido ser difundidas mediante la planimetría tradicional. 
Sin embargo, en la iconografía histórica si es posible encontrar lo que buscamos. En ella existe una gran variedad de representaciones de la ciudad medieval. La encontramos esculpida en piedras, bronce ó marfil, en capiteles, en tímpanos, en sellos y sobre todo en pinturas.

El estudio de las representaciones urbanas del arte medieval nos permite restituir, en parte, la fisonomía de la ciudad (Arizaga, 1996). La representación urbana del siglo XIII combina dos elementos: el continente que equivale al lugar urbano, representado como un recinto flanqueado por torres y el contenido que se identifica con los componentes urbanos esenciales de la ciudad: las torres, las iglesias o el castillo.

Figura 8: La Jerusalén celestial

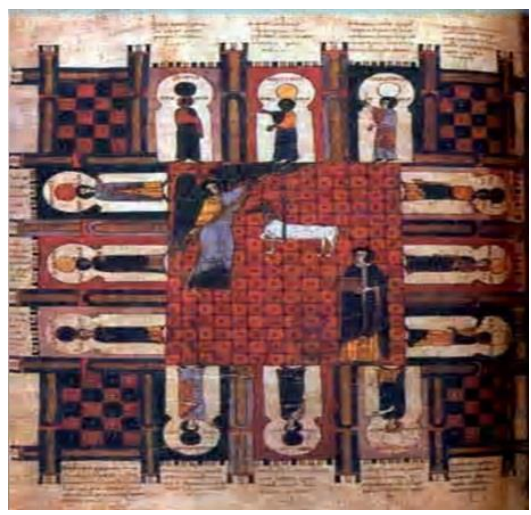

\section{Fuente: Ilustración del Beato de Facundo Siglo XI. Biblioteca Nacional de España.}

Casi todas las imágenes urbanas de la época responden al arquetipo de ciudad ideal, la Jerusalén celestial del Apocalipsis (figura 8), que se describía como una ciudad cuadrada de doce puertas, tres por cada lado, con una geometría reticular y ortogónica. Por lo tanto, la representación iconográfica podría haber servido de planimetría para el levantamiento de las ciudades ya que representa a la perfección la morfología de la ciudad medieval. Aunque también se necesitaría definir unas ordenanzas de trazado para corroborar que existió una planificación de la ciudad.

\section{Las Cantigas de Santa María}

Llegado este momento habría que preguntarse qué obra del rey sabio podría recoger las reglas para el trazado de la ciudad, en cual existen representaciones pictóricas de la misma. Y la respuesta es sorprendente: las cantigas de Santa María, que casualmente es un cancionero musical. $\mathrm{Y}$ digo casualmente porque al contener pinturas de las villas donde tienen lugar las hazañas que se describen en sus canciones y partituras en las que queda escrita la melodía, incluye la cuarta arte que hasta el momento no se había tenido en cuenta como fundamental para el trazado de la ciudad: la música. Es decir, en el Cancionero están recogidas implícitamente, las cuatro artes que formaban el Quadrivium y que según Pitágoras eran fundamentales para el funcionamiento del universo. Artes que, de acuerdo con los postulados de Tomás de Aquino y según se ha deducido, también estarían detrás del acto fundacional de una ciudad. Por lo tanto cabe preguntarse si sería el códice de las Cantigas el documento que contenía las ordenanzas de trazado de una ciudad.

Existen algunas obras que lo han señalado como un documento de gran valor para conocer los aspectos de la ciudad medieval, como las de J. Guerrero Lovillo (1949), F.J. Sánchez Cantón (1054), A. Domínguez Rodriguez (1998) ó G. Menéndez Pidal (1986). Obras a las que hace referencia Adrián Arcaz (2006:77) en su estudio sobre la imagen de la ciudad en Las Cantigas, donde dijo textualmente: "El Códice Escurialense......... ofrece un verdadero arquetipo de imágenes que reconstruyen visualmente los que sería la configuración real de las ciudades en la época de Alfonso X". Todos describen la ciudad representada en las viñetas, cercada casi siempre por un recinto murado reforzado por torreones, y en el que destaca la puerta como elemento fundamental (figura 9). Hablan de algunos de sus componentes urbanos, de su emplazamiento e incluso de su forma de construcción, pero ninguno pormenoriza en la morfología de su tejido urbano. Debido a la ausencia de la perspectiva es difícil deducir desde las viñetas la geometría de su trama urbana, 
no obstante, si se tiene en cuenta la constante representación de plazas en las mismas (figura 9), es posible dilucidar sobre ella. Por un lado, Torres Balbás (1954) afirmó que al mismo tiempo que en Levante empezaba a cambiar el concepto de ciudad, surgía la idea de plaza como expresión de la grandeza cívica. Palabras en las que se basó Betrán Abadía (1992) para hablar de la aparición de la plaza en la ciudad medieval, resaltándola como el elemento indicativo de un nuevo modo de crear la ciudad, el elemento generador y jerarquizador del plano, el nuevo centro urbano designado en una planificación previa de la ciudad. Por otro Arizaga Bolumburu explicó que las imágenes urbanas representadas en la iconografía histórica responden al arquetipo de la Jerusalén Celestial. Por lo tanto, podría ser que en las viñetas se estuviese representando una nueva ciudad medieval que recordaba a la antigua ciudad clásica, aquella que postulaba Aristóteles, y que tanto alababa Santo Tomás De Aquino, una ciudad perfectamente regular. Aunque aún sigue en pié la pregunta planteada en líneas anteriores, ¿Cuáles eran las ordenanzas de trazado que guiaron la construcción de la ciudad?

\section{Figura 9: Miniaturas de las Cantigas de Santa María}

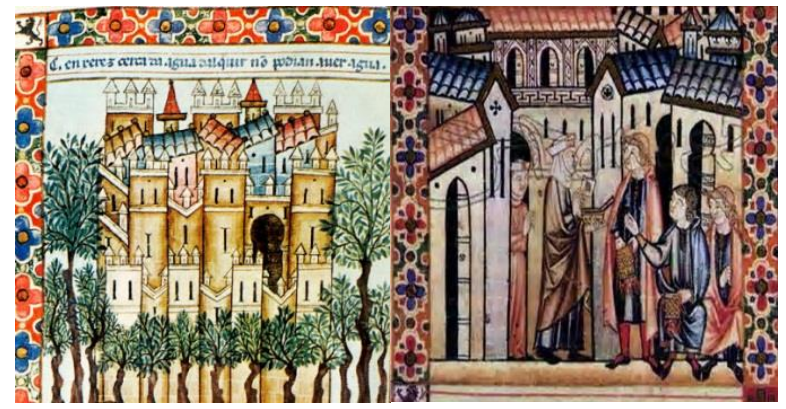

Fuente: Códice de Nicolo da Bologna Las Virtudes y las Artes de 1355. Biblioteca Ambrosiana de Milan.

\section{Las Ordenanzas Alfonsinas}

Después de lo descrito puede resultar obvio subrayar que la obra de las Cantigas (figura 10) ha sido estudiada en profundidad no sólo desde el punto de vista histórico, y pictórico, sino también como tratado musical, insistiendo en la composición de la melodía, y la aplicación del sistema notacional. Sin embargo, se me hace completamente necesario remarcar que nunca se ha buscado relación alguna entre el cuerpo musical de la obra y el hecho que se está narrando, entre las "leyes" por las cuales toma vida la composición y los acontecimientos que se cuentan, entre la estructura precisa de la métrica y la ciudad donde sucede el milagro, entre la melodía y la morfología urbana, entre la música y la ciudad.

Dado el momento histórico que nos ocupa, en el que el saber permanecía oculto en los monasterios, el poder del Islam estaba casi doblegado y el proceso de repoblación se erigía como fundamental para consolidar la Reconquista, me pregunto si los códices de las Cantigas, tan apreciados por Alfonso X, además de ilustrar a la perfección las ciudades medievales en las que tuvieron lugar las "hazañas" que narran, contienen también una detallada descripción acerca de la ciudad, "de la forma que debían tener y del modo de construirlas". Si se utilizaron los mecanismos de transmisión propios del sistema gremial recurriendo al secretismo metodológico acentuado por la inexistencia de la imprenta. Si Alfonso $\mathrm{X}$, tan interesado por la cultura, llevó hasta su última instancia las teorías de los clásicos, dejando por escrito las relaciones armónicas sobre las que debían de construirse la ciudad. Si existe algún "código" en forma de música que contenga directrices sobre el diseño de la traza urbana. Si a través de sus partituras, del análisis rítmico y melódico de las mismas, no descifraré "leyes" que también sean aplicables a la ciudad, si al contrario de lo que se ha pensado durante siglos, si existían, aunque ocultas en la melodía directrices sobre la forma, el modo de construir la ciudad y los elementos esenciales de la misma. En definitiva, si descifraré las ordenanzas de trazado de la ciudad. 


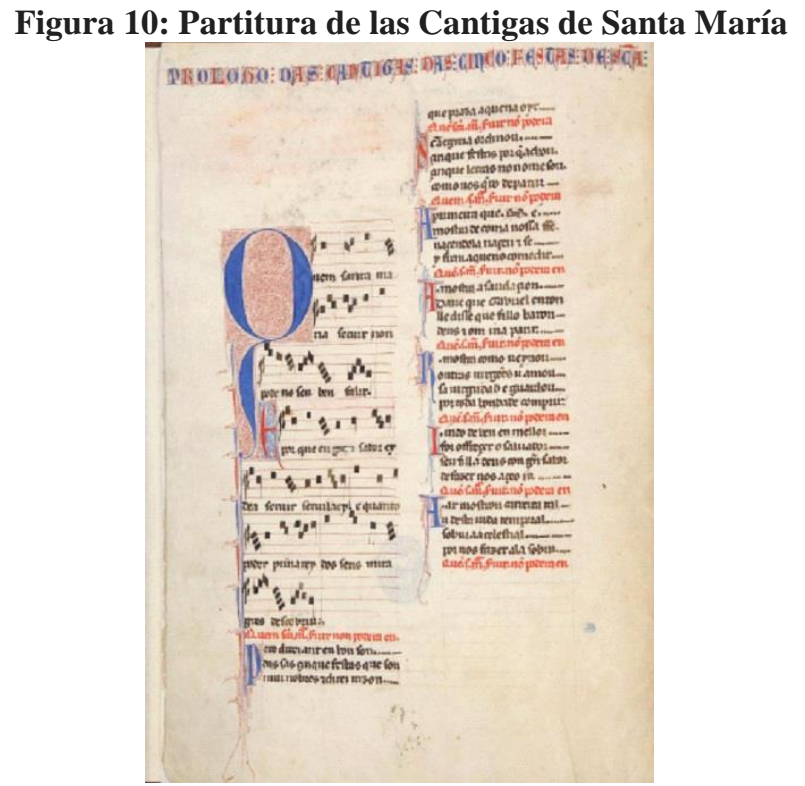

Fuente: Códice Escurialense. Monasterio del Escorial.

Ya lo decía Leibniz la música es un "excercitium arithmeticae ocultum nescentis se numerari animi". Schopenhauer (2002: 83) la describió como "un arte tan elevado y tan admirable, obra tan poderosamente sobre el sentimiento más íntimo del hombre, y la comprendemos tan a fondo y tan enteramente, como una lengua universal, cuya claridad supera hasta la del mundo intuitivo".

La música no se puede ver ni tocar, únicamente se puede oír de tal manera que su interpretación conecta directamente con el alma, te engrandece y te transporta, verdaderamente te emociona. Por esto al escucharla, no reparamos como sucede con otras artes, en las técnicas de composición empleada, en la relación existente con otras "ciencias", ni en la combinación de leyes aritméticas y geométricas con las que se han escrito sus partituras. Sin embargo, si nos detenemos en el estudio de estos elementos, en el análisis melódico y rítmico de la música, encontraremos las claves que marcan la relación que buscamos, la relación entre la música y la ciudad.

\section{Las proporciones numéricas con las que se construye la melodía}

Comenzando con el análisis melódico me detengo en el estudio de los clásicos, de cuyas enseñanzas se descifran los principios aritméticos y geométricos en base a las cuales se construyó la melodía y de los que se sirvió Boecio (siglo VI), para elaborar su fantástico tratado sobre aritmética, De Institutione Arithmeticae, (Sánchez, 2002) que se convirtió en la base de la teoría musical melódica que desarrolló años más tarde en su tratado De música (Vollegas, 2005).

Pitágoras (siglo VI a.c) subrayaba que el número era la esencia de todas las cosas, el principio común de las cuatro ciencias que regían el universo, el que provocaba que existiese entre la geometría, la aritmética, la astronomía y la música una unión indisoluble. Sus teorías fueron muy significativas en lo que a la perfecta configuración urbana de la Grecia clásica se refiere, y así lo demostró Mileto construyendo la ciudad ortogonal Hipodámica. Al analizar el plano en forma de damero resulta evidente la geometría, la aritmética e incluso la astronomía empleada para su elaboración, pero cae en el olvido la cuarta ciencia que Pitágoras definió como imprescindible para que el Universo funcionase: la música.

Explicó la consonancia musical y su fundamentación matemática (Tomassini, 2007). Definió la música como una rama de las matemáticas, y como la auténtica responsable de la estrecha unión existente entre la geometría y la aritmética. Los Pitagóricos no dejaron registros escritos de sus teorías por lo que hay que recurrir a manuscritos de otros filósofos para descubrirlas (Miyara, 2005). Así, la conocida teoría en la que se pone de manifiesto la concordancia entre las proporciones geométricas, aritméticas y musicales, explicada por Platón en su libro la República, la música de las esferas, fue comentada por Aristóteles diciendo textualmente, "algunos pensadores suponen que el movimiento de los 
cuerpos celestes debe de producir un sonido, dado que en la tierra el movimiento de cuerpos de mucho menor tamaño produce dicho efecto. Afirman también, que cuando el sol, la luna y las estrellas, tan grandes y en tal cantidad, se mueven tan rápidamente ¿cómo podrían no producir un sonido inmensamente grande? A partir de este argumento y de la observación de que sus velocidades, medidas por sus distancias, guardan igual proporción que las consonancias musicales, aseveran que el sonido proveniente del movimiento circular de las estrellas corresponde a una armonía" (Candel, 1996:155).

Utilizó el monocordio para demostrar, que la subdivisión de una cuerda vibrante en segmentos que guardaban una proporción aritmética producía sonidos armoniosos altos y bajos, y que si dos de ellos se tocaban simultáneamente producían sonidos consonantes. En definitiva, encontró proporciones numéricas entre la longitud de una cuerda y las notas de la escala musical. (figura 11). "En la actualidad las notas no se definen a partir de la longitud del objeto vibrante, sino a partir de la frecuencia de vibración de la onda sonora que emite el objeto" (Tomassini, 2007:15).

Arquitas de Tarento (siglo V a.c) afirmó que en la música existían tres medias: "la primera es la media aritmética, la segunda es la geométrica, y la tercera es la media subcontraria llamada armónica..." (Sylvan, 1987:185). Las medias especificadas por Arquitas se identifican con proporciones matemáticas, proporciones de las que obtenemos hoy en día, si aplicamos los valores de las frecuencias vibratorias de cada nota, los distintos intervalos de la escala. De la aritmética nace el de quinta; de la armónica, el de cuarta; y de la geométrica, la octava, y el tono surge del cociente entre la aritmética y la armónica. Así, dado que la proporción armónica define la relación de una nota con su cuarta perfecta, y la aritmética con su quinta, podremos decir que la escala musical presenta simetría en su estructura matemática (Tomassini, 2007) (figura 12).
Figuras 11 y 12: Los experimentos de Pitágoras y Diagrama representativo de la simetría y las proporciones que guardan las notas que construyen la escala musical.

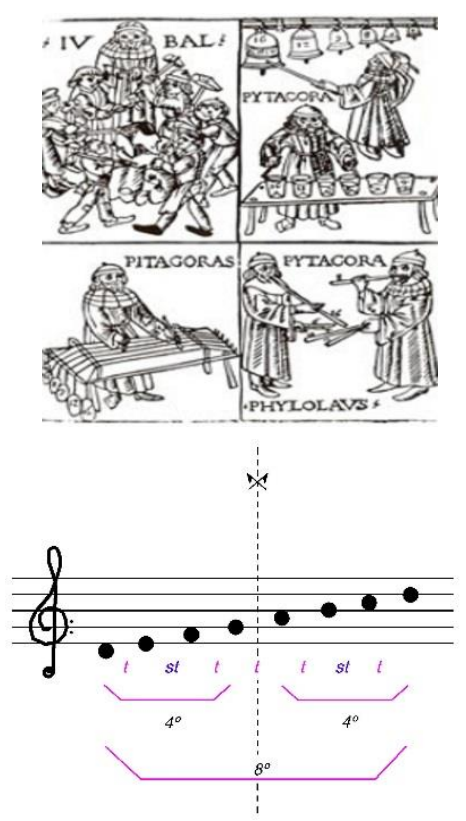

Fuente: Izquierda: Grabado del siglo XVI. GAFORIUS. Extraido de "Geometría Sagrada" de Lawlor, 1996. Derecha: Elaboración propia.

Euclides (siglo IV a.c) desveló la existencia de un número divino, el número áureo (De Tomás, 2016). Y lo definió como la esencia de todo lo armónico, como el verdadero responsable de la armonía universal. El origen de la divina proporción fue explicado a partir de la división de una recta en dos partes de modo que la razón entre la mayor y la menor sea igual a la razón entre la recta completa y la parte mayor. Es decir, si $\mathrm{AB}$ es la recta y $\mathrm{C}$ el punto intermedio: $\mathrm{AB} / \mathrm{AC}=\mathrm{AC} / \mathrm{CB}$. En definitiva, tal y como dijo Miyara (2005), se puso de manifiesto la intrínseca relación existente entre la geometría y la aritmética.

La pintura, la escultura, la arquitectura y la música, han utilizado la divina proporción en sus métodos compositivos logrando la belleza de sus obras. Así, Mozart dividió el segundo movimiento de la sonata $\mathrm{n}^{\circ} 1$ para piano en 28 y 46 compases, introduciendo a través del cociente de la proporción 46/28=1,6428 un número 
muy cercano al áureo; Bela Bartok también se sirvió de este número divino para la estructuración de su obra "Fuga para cuerdas, percusión y Celesta" y se podría decir que Alfonso $\mathrm{X}$ también lo utilizó para componer sus queridas cantigas.

Llegado este momento, después del estudio realizado y teniendo en cuenta que las notas de la escala musical se definen a partir de la frecuencia de vibración de la onda sonora emitida por una cuerda vibrante según las proporciones aritméticas en las que se puede subdividir, lo que resalta el número como parte de sus esencia; que la escala es simétrica en su estructura matemática, y que respetando esta simetría casi todas las partituras de las Cantigas comenzaban con la nota RE y que el número áureo, el paradigma de la belleza también está presente en la composición melódica de las cantigas, se podría afirmar que los principios compositivos utilizados en la música de Las Cantigas son los mismos que subyacen en el trazado de una ciudad. Y que la perfecta ciudad, será aquella en la que se apliquen la simetría, la proporción, y el orden como principio jerarquizador de lo urbano, la que nazca de las relaciones numéricas con las que se alcance la armonía y la belleza, aquella en la que esté implícita para su concepción el número áureo, y esta será: la ciudad ortogonal. La alabada por Aristóteles, la defendida por Tomás de Aquino, la representada en la Jerusalén Celestial. Por lo tanto, podrían ser la proporción, la simetría, y la armonía áurea, tres de las cinco ordenanzas dictadas por el rey sabio, para la construcción de la perfecta ciudad.

\section{La significación del ritmo en la articulación urbana}

Para concluir este somero análisis sobre la música es necesario detenerse en el otro pilar sobre el que se sustenta: el ritmo, que al contrario que la melodía, es mucho más evidente en el tejido de la ciudad. Forma parte de su traza, de la disposición de sus componentes urbanos, de la separación entre el espacio público y el privado, en definitiva, de su morfogénesis. En música nace de la relación de los sonidos según la desigualdad de duración de los mismos, por esto el ritmo y su medida son fundamentales para articular cualquier melodía.

El ritmo existe desde el principio de los tiempos, aunque no siempre se ha medido. A comienzos de la Edad Media, la música se escribía aún con notación no mensural, esto es sin medición, las obras carecían de una medición rítmica exacta y la melodía sonaba según la libre interpretación del músico que la tocaba. El Códice de Las Cantigas supuso un punto de inflexión en este tema, y en él se aplicó por primera vez en Castilla, la notación mensural. Sus partituras están escritas con una medida exhaustiva del ritmo, las figuras que sostienen las notas tienen un valor determinado, y esto hace posible una única interpretación de la obra, porque en ella queda representada con exactitud el ritmo y la melodía.

Antes de seguir avanzando en este tema es necesario detenerse en la fantástica obra que elaboró Francisco Salinas (siglo XVI) (Fernández, 2010) acerca de las estructuras rítmicas de la música, donde sacó a la luz el tratado De música de San Agustín (siglo IV), centrado únicamente en el estudio de los aspectos rítmicos de la música. Salinas consideró que los tratados de Boecio y San Agustín eran complementarios porque cada uno de ellos se centraba en el estudio de uno de los pilares sobre los que construía la música: la melodía y el ritmo.

San Agustín explicó los elementos y la estructura del ritmo musical, para terminar, estudiando los números eternos que definió como la razón y la causa de toda organización rítmica. En su pensamiento neoplatónico subyacen los postulados Pitagóricos según los cuales el numero esa la esencia de todas las cosas.

A la vista de lo descrito, no cabe ninguna duda que profundizar en el análisis rítmico de Las Cantigas resulta bastante complejo, sin embargo, sin llegar a desbordar el objeto de la investigación, no se puede renunciar a tocar 
sensiblemente algunos de sus aspectos fundamentales dada la importancia de la aparición de la notación mensural en el Códice de Las Cantigas y su influencia decisiva en la morfogénesis urbana.

Franco de Colonia fue uno de los mejores tratadistas del Medievo. En su tratado musical hizo un estudio exhaustivo de los "modos y las figuras rítmicas" aportando una sistematización casi completa de la música mensural. Estudió, entre otras muchas cosas, la importancia de medir el tiempo para componer una obra, y afirmó que el modo ternario, el formado por tres tiempos, era el perfecto, ya que aludía directamente a la Santísima Trinidad. Profundizó en el estudio de las figuras rítmicas fundamentales para representar la duración de los sonidos y sostuvo que era la longa perfecta, la figura perfecta, valga la redundancia, para cualquier composición musical, precisamente por durar tres tiempos.

Con todo ello, López Elum (2005), en su obra "Interpretando la música Medieval" aporta un interesantísimo dosier de cantigas transcritas a la música actual. El modo ternario lo traduce al compás de 3/4 y la longa a la figura que ocupa la unidad de tiempo de dicho compás, la negra, matizando que será perfecta cuando ocupe todo el compás.

Es importante aclarar que, en música, el compás se define como el "elemento" que organiza el tiempo en partes iguales, y se utiliza para medir la duración de los sonidos, es decir el tiempo musical. Las figuras, por su parte, representan la duración de los sonidos y se adecuan al compás en el que se integran. En definitiva, el compás organiza la composición, la estructura y la mide, y es el que decide las figuras que lo integran, así como el número de tiempos en los que se dividirá. En vista de lo descrito, haciendo un análisis rítmico del cuerpo de las Cantigas, podemos entender lo que supuso la notación mensural en la obra, y la importancia del ritmo y su medida. Ritmo que, como decía en líneas anteriores subyace en la traza de la ciudad.

Por lo tanto, del análisis rítmico de una partitura se podría deducir el elemento generador de lo urbano y la célula básica necesaria para la construcción de la ciudad. Así, si la perfección musical del medievo, la encarna el compás de 3/4, la utilización de dicho compás siempre nos estará remitiendo a la utilización de la traza perfecta para la construcción de la ciudad, aquella que asegure la igualdad entre los hombres, la que defendía la vieja democracia ateniense, la inmortalizada en la Jerusalén celestial, esa que se advirtió en líneas anteriores: la ciudad ortogonal.

La traza organiza, estructura e interrelaciona las distintas partes de la ciudad. En su recorrido marca la separación y el contraste entre el espacio público y el privado, introduce, sin lugar a dudas, el ritmo en la composición urbana. Pero este ritmo, está medido por el compás cuya utilización hace que también midamos la traza y está ejecutado por distintas figuras que son las que hacen que suene la melodía. Blancas, negras, corcheas, semicorchas, que nacen y adquieren su valor relativo, al relacionarse con una que representa la unidad musical: la redonda (figura 13). Las distintas figuras con las que se caracterizan las notas para representar la duración de los sonidos nacen de la redonda, es decir, todas ellas guardan una proporción matemática, y están interrelacionadas entre sí. De este modo una redonda equivaldrá a dos blancas, cuatro negras, ocho corcheas, 16 semicorcheas, y otros. 
Figura 13: Nacimiento de las distintas figuras rítmicas y composición musical.

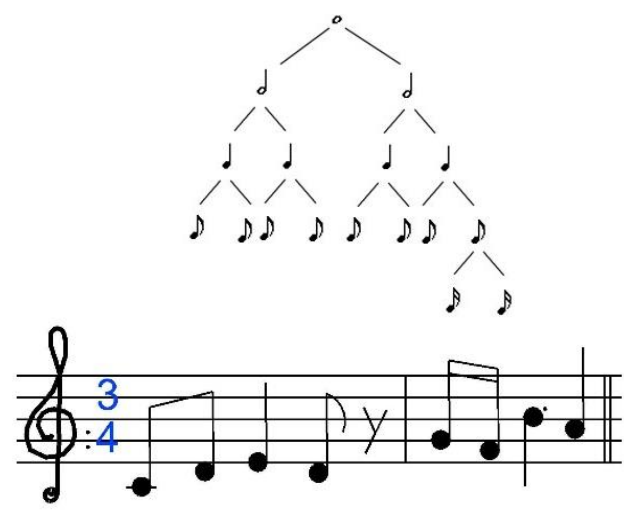

Fuente: Elaboración propia

Llegado este punto faltaría por identificar que elemento de la traza representaría la unidad urbana, al igual que la redonda representa la unidad musical. ¿Cuál sería el nuevo elemento generador de la traza en la ciudad del medievo, el responsable de su estructura y de su organización? La respuesta es evidente: la plaza, que como se dijo en líneas anteriores, también representa el nuevo modo de concebir la ciudad (Torres, 1954). Es el centro neurálgico del tejido, y el elemento generador de lo urbano, el responsable de la nueva cualificación espacial y jerarquizadora del espacio público, es el elemento que empieza a garantizar un trazado urbano homogéneo e igualitario en el que la iglesia y el castillo pierden su autoridad.

A mi entender su papel en la ciudad, es claramente identificable con el que la redonda tiene en música, porque representa la simetría, la proporción, la armonía, en definitiva el origen del trazado urbano. Por esto, aunque no aparezca escrita en la partitura, en realidad siempre está, porque las figuras nacen de ella, toman su valor según relaciones matemáticas aplicadas a ella, y es sin duda alguna la matriarca del ritmo, al igual que la plaza de la ciudad. Será la plaza la que genere la traza que dibuje las alineaciones, la que marque la separación entre el espacio público y el privado, la que interrelacione los componentes urbanos, la que permita la circulación y la que introduzca el ritmo en la ciudad, y de ella al igual que ocurre con la redonda, de las proporciones matemáticas que generan las distintas figuras rítmicas se obtendrá la célula urbana, la conformada por la manzana y la calle, aquella que tras la aplicación de las distintas ordenanzas alfonsinas nos permitirán construir la ciudad.

Por lo tanto, podrían ser la ortogonalidad y la generatriz urbana las dos ordenanzas de trazado descubiertas tras el análisis rítmico de la música del medievo, que sumadas a las otras tres conforman el legado que dejó Alfonso X para la construcción de la ciudad regular. Legado que se extrae del análisis melódico y rítmico de la música escrita en las Cantigas, porque es en ellas, donde se descifran las reglas de composición musical dictadas por los clásicos, y donde por primera vez en Castilla se utilizó la notación mensural. Así las cinco ordenanzas forman un "pentagrama" de normas, originadas por las doctrinas pitagóricas, tocado por la belleza áurea y consolidado por el saber y el ingenio Alfonsino que recuperaron la perfecta regularidad de las antiguas ciudades clásicas.

Ordenanzas subyacentes en las villas de Villaviciosa, Mondragón y La puebla del Río, que fueron trazadas conforme a los mismos principios compositivos que rigieron la elaboración de música del Códice, por lo que se podría afirmar, tomando en consideración las alusiones aristotélicas a la ciudad hipodámica como ciudad ideal en la que se concentraba todo lo especificado, que dado que el trazado urbano requiere de la combinación de leyes geométricas y aritméticas para su realización, bajo el plano de cualquier ciudad subyace, como si de un palimpsesto se tratase: la música.

\section{Conclusiones}

Tras el estudio realizado se podría afirmar que la asombrosa regularidad de las pueblas construidas por el rey Alfonso X "El sabio" responde a la existencia de unas normas de trazado fraguadas a raíz de las teorías 
postuladas por los clásicos, redescubiertas durante el renacimiento cultural.

También se podría corroborar que la aparición de la plaza como nuevo elemento generador de lo urbano confirma la existencia de una concepción previa de la ciudad, que utiliza como planimetría la iconografía de la época y como ordenanzas de trazado, unas reglas escritas en un lenguaje que, siguiendo el secretismo metodológico utilizado en el sistema gremial, no era el tradicional, aunque sí completamente universal: la música.

En consecuencia, se podría decir que el documento de Las Cantigas de Santa María fue el escogido para este fin, y que, del análisis de sus partituras, del estudio de las claves rítmicas y melódicas con las que se compusieron, se deducen las mismas leyes aritméticas y geométricas que fueron utilizadas para elaborar las normas de trazado de las ciudades levantadas por el rey sabio.

Lo que se reafirma tras el reconocimiento de los tejidos urbanos de las ciudades de Villaviciosa, Mondragón y la Puebla del Río, pues su análisis aporta información imprescindible para el entendimiento del patrón urbano subyacente en ellos y para el esclarecimiento de sus características geométricas principales. La proporción, la simetría, la armonía, la ortogonalidad y la generatriz urbana, emergen como ordenanzas de trazado. Características que como hemos visto también fueron utilizadas en la composición melódica y rítmica de las Cantigas.

El estudio realizado es tremendamente novedoso y significativo porque además de desvelar las ordenanzas de trazado que dirigieron el levantamiento de las ciudades alfonsinas pone de manifiesto que gracias al nuevo sistema de pensamiento desarrollado en la época el hombre medieval consideraba una concepción previa de la ciudad. Sentido en el cual, se podría afirmar que, a partir de ese momento histórico, todas las ciudades fundadas en los reinos cristianos de la Península se fraguaron en torno a un patrón urbano perfectamente pensado y elaborado, en el que destacaba el orden como principio jerarquizador de lo urbano. Lo que a su vez permite asegurar que fue en el bajo Medievo cuando se consolidaron los fundamentos urbanos sobre los que se recuperó el antiguo trazado urbano regular.

Además, el descubrimiento de la común unión entre las reglas de composición musical y las del trazado originario de una ciudad nos desvela la importancia de la música como "nuevo" agente urbanizador de la ciudad, abriéndonos una nueva línea de intervención urbana completamente extrapolable a la actualidad.

\section{Referencias bibliográficas}

Achón Insausti, J.A (1995): A voz de concejo. Linaje y corporación urbana en la constitución de la Provincia de Gipuzkoa: los Báñez y Mondragón, siglos XIII-XVI. San Sebastián, Diputación Foral de Gipuzkoa.

Anglés, H. (1958): "La música de las Cantigas del Rey Alfonso X el Sabio". Facsimil. Diputación Provincial, Biblioteca Central, Vol I, 1964, vol II. 1943, vol III, en dos partes.

Arcaz Pozo, A. (2006): "La imagen de la ciudad Castellana en las Cantigas de Santa María” en Gonzalez Jimenez, M. El mundo urbano en la Castilla del siglo XIII. Vol II. Sevilla. Ayuntamiento de Ciudad Real, Fundación el Monte.

Arizaga Bolumburu, B. (1978): El nacimiento de las villas guipuzcoanas en los s.XIII y XIV: morfología y funciones urbanas, San Sebastián, Sociedad guipuzcoana de ediciones y publicaciones.

Arizaga Bolumburu, B. (1996): "La recuperación del paisaje urbano medieval: propuesta metodológica" en Bonachía Hernando, J.A, La ciudad medieval. Aspectos de la vida urbana en la Castilla bajomedieval. Valladolid, Universidad de Valladolid.

Arizaga Bolumburu, B. (2010): Apuntes de Historia urbana medieval. Departamento de Ciencias Históricas. Universidad de Cantabria.

Aymonino, C. (1983): El significado de las ciudades. Hermann Blume.

Benito Martín, F. (2000): La formación de la ciudad medieval. Valladolid, Universidad de Valladolid. 
Betrán Abadía, R. (1992): La forma de la ciudad: Las ciudades de Aragón en la Edad Media. Zaragoza, Colegio oficial de arquitectos de Aragón.

Betrán Abadía, R. (1994): "Las huellas del tiempo: parcelario, tipo y propiedad" en VV.AA, Paisajes rurales y paisajes urbanos: métodos de análisis en historia medieval. Zaragoza. Departamento de Historia Medieval, Ciencias y Técnicas Historiográficas y Estudios árabes e islámicos.

Bielza de Ory, V. (2002): "De la ciudad ortogonal aragonesa a la cuadricular Hispanoamericana como proceso de innovación-difusión condicionado por la utopía”, Scripta Nova, vol VI, Nº106.

Borrero Fernández, M. (2010): "Realidad económica y social de los vecinos de La Puebla del Río en la Edad Media tardía" en Escacena Carrasco, Jose Luis, La Puebla del río. Miscelánea histórica. Sevilla. Universidad de Sevilla.

Candel, M. (1996): Aristóteles. Acerca del cielo. Meteorologicos. Madrid Editorial Gredos.

Caniggia, G. (1981): Composizione architettonica e tipología edilizia (Architettura e urbanística). Marsilio.

De Tomás Medina, C. (2016): “Las ciudades suenan”, Mina 3, Año VII $\mathrm{N}^{\circ} 15$, pp. 7-10.

Dominguez Rodríguez, A. (1998-9): "El arte de la construcción y otras técnicas artísticas en la miniatura de Alfonso X El sabio", Alcanate 1, pp. $59-83$

Fernandez de la Cuesta, I. (2003-04): "Claves de retórica musical para la interpretación y transcripción del ritmo de las Cantigas de Santa María", Revista del Real Conservatorio Superior de Música de Madrid, nº10-11, pp. 19-54.

Fernandez de la Cuesta, Ismael (2010): Siete libros sobre la música. Traducción del libro de Francisco Salinas. Madrid, Alpuerto, S.A.

Frugoni, C. (1991): "Una ciudad en imágenes, ciudades imaginadas" en RIERA Palmero, J, Representaciones de la sociedad en la historia: de la autocomplacencia a la utopía. Valladolid. Instituto de historia Simancas.

García de Cortázar, J.A (1985): Organización social del espacio en la España medieval. La corona de Castilla en los siglos VIII al XV. Barcelona, Ariel.

Gonzalez Jimenez, M. (2006): “Alfonso X, repoblador" en Gonzalez Jimenez, Manuel, El mundo urbano en la Castilla del siglo XIII. Vol I Sevilla. Ayuntamiento de Ciudad Real, Fundación el Monte.
González Jimenez, M. (2010): “Alfonso X El Sabio (1252-1284)" en Escacena Carrasco, Jose Luis, La Puebla del Río. Miscelánea histórica. Sevilla, Secretariado de publicaciones de la Universidad de Sevilla, pp.26.

Guerrero Lovillo, J. (1949): Las Cantigas, estudio arqueológico de sus miniaturas. Madrid.

Lacarra, J.M. (1948): "La repoblación de las ciudades en el camino de Santiago: su trascendencia social, cultural y económica”, en Vázquez de Parga; L; Lacarra, J.M. y Uría Ríu, J. Las peregrinaciones a Santiago de Compostela I. Madrid, Consejo superior de investigaciones científicas, escuela de estudios medievales.

López Alsina, F. (1976): Introducción al fenómeno urbano medieval gallego a través de tres ejemplos: Mondoñedo, Vivero y Ribadeo. Santiago, Universidad de Santiago.

Lopez Elum, P. (2005): Interpretando la música Medieval. Las Cantigas de Santa María. Valencia, Universidad de Valencia.

Mariño Sánchez-Elvira, R. Mํ; Mas Torres, S.; García Romero, F. (2008): La República. Platón. Madrid, Ediciones Akal, S.A.

Medianero Hernández, J.M. (2004): Historia de las formas urbanas medievales. Sevilla, Universidad de Sevilla.

Menéndez Pidal, G. (1986): La España del siglo XIII leída en imágenes. Madrid, Real Academia de Historia.

Miyara, F. (2005): "La música de las esferas: de Pitágoras a Xenaquis...y más acá”, Apuntes para el coloquio del Departamento de matemática, pp. $1-19$.

Moxó, S. (1978): Repoblación y sociedad en la España Medieval. Madrid, Ediciones Rialp, S.A.

Muratori, S. (1960): Studi per una operante storia urbana di Venezia, Roma, Instituto poligrafico dello stato.

Pardo Rodríguez, M.L. (2010): "Los privilegios rodados de La Puebla del Río" en Escacena Carrasco, Jose Luis, La Puebla del río. Miscelánea histórica. Sevilla. Universidad de Sevilla.

Rossi, A. (1982): La arquitectura de la ciudad. Gustavo Gili, Barcelona.

Ruiz de la Peña, J.I. (1981): Las polas Asturianas en la Edad Media. Oviedo, Universidad de Oviedo.

Sainz Guerra, J.L. (1990): La génesis de la plaza en Castilla durante la Edad Media. Valladolid, Colegio oficial de arquitectos de Valladolid. 
Sánchez Cantón, F.J. (1954): “Alfonso X y la pintura sobre tabla”, Archivo Español de arte, pp. 41.43.

Sánchez Herrero, J. (1981): Cádiz, la ciudad medieval y cristiana. Córdoba, Caja de Ahorros.

Sánchez Manzano, M.A (2002): De Institutione Arithmeticae. Traducción de Severino Boecio. León, Universidad de León.

San Agustín (1988): "Obras completas de San Agustín”, Biblioteca de autores cristianos. vol, 39, pp. 70-361.

San Martín, A. (1872-1873): Los Códigos Españoles concordados y anotados. Vol 2-5. Código de las siete Partidas. Madrid.

Schopenhauer, A. (2002): El mundo como voluntad y representación III y IV. Barcelona, Ediciones folio, S.A.

Serra Rafols, E. (1968): La repoblación de las islas Canarias. Barcelona, A.E.M.

Sylvan Guthrie, K. (1987): The pythagorean Sorcebook and Library. Michigan, David R. Fideler.

Tomás de Aquino, Summa Theologiae I.II, q.57, a.3.

Tomasini, M.C. (2007): "El fundamento matemático de la escala musical y sus raíces Pitagóricas", C\&T Universidad de Palermo, pp.15-27.

Torres Balbás, L; García y Bellido, A; Chueca Goitia, F; Bidagor (1954): Resumen histórico del Urbanismo en España. Madrid, Instituto de Estudios de la Administración local.

Vollegas Guillén, S. (2005): Tratado de música. Traducido de Severino Boecio. Madrid, Ediciones clásicas. 
